OPEN ACCESS

Edited by: Tzvi Dwolatzky

Technion Israel Institute of Technology, Israel

Reviewed by:

Judith Sixsmith,

University of Dundee, United Kingdom

David X. Marquez,

University of Illinois at Chicago,

United States

*Correspondence:

Caroline D. Bergeron

caroline.bergeron2@canada.ca

Specialty section:

This article was submitted to

Aging and Public Health,

a section of the journal

Frontiers in Public Health

Received: 02 March 2021

Accepted: 11 June 2021

Published: 12 July 2021

Citation:

Bergeron CD, Boolani A, Jansen EC

and Smith ML (2021) Practical

Solutions to Address

COVID-19-Related Mental and

Physical Health Challenges Among

Low-Income Older Adults.

Front. Public Health 9:674847.

doi: 10.3389/fpubh.2021.674847

\section{Practical Solutions to Address COVID-19-Related Mental and Physical Health Challenges Among Low-Income Older Adults}

\author{
Caroline D. Bergeron ${ }^{1,2 *}$, Ali Boolani ${ }^{3,4}$, Erica C. Jansen ${ }^{5,6}$ and Matthew Lee Smith ${ }^{2,7}$ \\ ${ }^{1}$ Public Health Agency of Canada, Division of Aging, Seniors and Dementia, Ottawa, ON, Canada, ${ }^{2}$ Center for Population \\ Health and Aging, Texas A\&M University, College Station, TX. United States, ${ }^{3}$ Department of Physical Therapy, Clarkson \\ University, Potsdam, NY, United States, ${ }^{4}$ Department of Biology, Clarkson University, Potsdam, NY, United States, \\ ${ }^{5}$ Department of Nutritional Sciences, School of Public Health, University of Michigan, Ann Arbor, MI, United States, ${ }^{6}$ Division \\ of Sleep Medicine, Department of Neurology, University of Michigan, Ann Arbor, MI, United States, ${ }^{7}$ Department of \\ Environmental and Occupational Health, School of Public Health, Texas A\&M University, College Station, TX, United States
}

Low-income older adults are disproportionately impacted by the COVID-19 pandemic. In this perspective article, we review the context in which low-income older people experience the pandemic and the mental and physical health consequences they have faced to date. Then, we offer practical solutions to help improve low-income older adults' sleep, physical activity, nutrition, and stress that require no or low financial commitment. We argue that governments, communities, and organizations should make greater efforts to promote healthy living for low-income older adults in times of health emergencies to ensure their ability to be universally adopted, regardless of income and resources.

Keywords: recommendations, physical health, mental health, older people, lower socioeconomic status

\section{INTRODUCTION}

In many ways, the novel coronavirus disease 2019 (COVID-19) pandemic has raised awareness about the importance of public health and gerontology. It is now common knowledge that handwashing, mask wearing, and physical distancing are effective public health measures to help reduce the spread of infection. Lockdowns and visitor restrictions have also been implemented in an attempt to minimize hospitalizations and deaths from COVID-19, especially among older adults who have been the most at-risk (1). The adoption of these protective measures to mitigate the spread of COVID-19 have paradoxically resulted in unintended short- and long-term mental and physical health consequences for older adults (2-6). Thus, alongside efforts to prevent COVID19 infection, disruptions in daily routines and lifestyle behaviors (e.g., physical activity, nutrition, sleep, social interactions) should not go overlooked. While there has been a surge in available resources and shifts in public health messaging to provide recommendations to older adults during the pandemic (7), specific recommendations are required for low-income older people $(8,9)$. Older adults with fewer financial resources and those who reside in more impoverished areas are often at a greater risk of COVID-19-related death $(10,11)$. Further, these older adults more frequently engage in unhealthy behaviors and have less access to healthful services, resources, and programs (12); which imposes barriers that limit their ability to self-manage their physical and mental health.

Herein, we present the results of our narrative literature review of the current knowledge on the mental and physical health of low-income older adults during the COVID-19 pandemic. For 
this perspective article, the literature review is not meant to be exhaustive, but aims to present an overview of recent literature about these key concepts (13). Through this narrative review, we contextualize the health consequences experienced by low-income older adults during the COVID-19 pandemic and offer practical recommendations to help them self-manage their physical and mental health. Using a socioecological perspective, we also provide public health recommendations beyond the individual level that could be implemented by governments, communities, and organizations for the well-being of low-income older adults.

\section{CONTEXT}

In the United States, approximately $87 \%$ of adults ages 65 and older were retired in 2016 (14), relying on social security benefits, pensions, retirement savings accounts, savings, and supplemental security income as their main sources of income (14). Approximately 50 million social security beneficiaries are people 65 and older; social security contributes to $90 \%$ of the family income in $25 \%$ of households (14). In 2018, retired workers on social security received an annual income of $\$ 17,535$ (15). Social security is not enough to cover out-of-pocket medical expenses (16), which may persuade patients to delay getting tested when they develop symptoms of COVID-19 or defer care and treatment in an attempt to avoid medical debt (17). If or by the time low-income older adults seek care, their condition may be worse with less chances of full recovery $(18,19)$. Uninsured or underinsured older Americans are at an increased risk of COVID-19 and its complications (20). Older African Americans are significantly more at risk of COVID-19 infections and mortality due to a variety of social determinants, including low income and lower rates of health insurance (21-23).

For older people who continue to work past retirement age, median earnings in 2018 were estimated at \$35,036 (14). Job losses during the pandemic have been predominantly in occupations with the lowest weekly earnings, including in retail, leisure, and hospitality sectors, where older women, Black, Indigenous and people of color (BIPOC), and immigrant populations are highly employed $(24,25)$. According to the Congressional Research Service (14), between January and September 2020, 8\% of older workers lost their jobs in the cleaning and maintenance sector, $10 \%$ in the food sector, and $28 \%$ in the personal care and service sector. BIPOC older adults working in sectors with high-contact, face-to-face interactions with the public may also choose to quit their jobs to reduce their risks of workplace exposure to COVID-19 (26).

The economic consequences of the pandemic have also contributed to greater rates of food insecurity among low-income households (27). In 2018, approximately 5.3 million older adults were food insecure (28); the number of food insecure older adults is expected to have significantly increased during the pandemic (28). Several reasons can explain this increase, including difficulty affording food (29), decline in food donations at food banks (30), trouble accessing food through a food pantry $(29,30)$, temporary closures of senior centers offering meals (30), challenges in getting food delivered by family or friends (29), less use of food delivery services or apps compared to other age groups due to related costs or access to technology (30), and fear of COVID exposure at the supermarket (30). Conversely, close to $20 \%$ of food-insecure adults are unable to buy 2 weeks of food at the same time to comply with the public health recommendations, thus increasing their risks of exposure to the virus (27).

\section{MENTAL HEALTH CONSEQUENCES}

The impact on the mental health of low-income older adults has been widely reported. Adults with low socioeconomic position were found to be the most at risk of experiencing moderate to severe depressive symptoms during the pandemic (31). Another study revealed that those who perceive to be personally at risk of COVID-19, including low-income older adults, experience greater depression and anxiety (32). Low-income older adults who test positive for COVID-19 may suffer fear, stigma, and post-traumatic stress symptoms from their experiences (3336). The general marginalization (37) of older people, requiring them to avoid intergenerational spaces (38), stay at home, selfisolate, and practice physical distancing from their families and friends, in addition to the digital divide (39), has contributed to further increasing the social isolation and loneliness of older people $(37,38,40-45)$, which was deemed an epidemic prior to COVID-19 (46-48). In addition, low-income older adults may have less access to technology than other older adults, making it difficult for them to maintain their social connections (49). Marginalization of older people also encourages ageist speech, behaviors, and policies (50-52), resulting in negative consequences for the health of older people, including reinforcing depressive symptoms, loneliness, and premature death $(51,53)$. An increase in alcohol consumption has been noted during the pandemic (54); low-income older adults are at risk of turning to substances such as alcohol and drugs to cope with financial stress, loneliness and grief (41), among other reasons, which may increase their risks for suicide (55-57). Older adults with preexisting mental health disorders may be more prone to relapse of substance misuse, social isolation, and suicidal behavior (58), especially due to limited access to mental healthcare services (58).

\section{PHYSICAL HEALTH CONSEQUENCES}

The pandemic has also impacted the physical health of lowincome older adults (59). Studies on COVID-19 around the world have reported a decrease in physical activity (4, 60-65) and an increase in sedentary behavior (i.e., sitting, reclining or lying down for long periods of time) (65-67) among older adults, which can significantly compromise an older person's cardiorespiratory fitness, muscle strength, and muscle mass (68, 69). Only 2 weeks of inactivity (e.g., 75\% less steps in a day) can result in an $8 \%$ reduction in muscle strength (70); conversely, more than 2 weeks of rehabilitation would be needed for older people to regain their initial muscle function (70). Muscle deconditioning can accelerate the progression of sarcopenia (69), contributing to frailty, reduced mobility, and falls $(4,63,71-73)$. 
Other studies reported that a decrease in physical activity of just 1,500 steps per day can worsen blood glucose control (74-76), increase body inflammation (77) aggravate existing chronic diseases (e.g., diabetes) $(74,78,79)$, and weaken the immune system (75), which may heighten an older person's risk to acute respiratory infections such as COVID-19 (75). Sedentary behavior is also associated with an increase in mental disorders such as depression and anxiety (80). Considering that low-income older adults are at greater risk for COVID19 , more prone to accelerated aging (81), chronic diseases, and disability $(81,82)$, and have reported poorer mental health during the pandemic (31) compared to the general older population, disrupting sedentary behavior and engaging in physical activity become especially important for this specific population $(79,83)$.

While malnutrition is generally considered to be an important issue for older adults $(84,85)$, it has continued to be a common occurrence during the pandemic (4). Older adults have experienced undernutrition, such as skipping meals due to food insecurity, as well as an overconsumption of unhealthy foods, such as sugar and saturated fats (4). Malnutrition can both increase the prevalence of chronic conditions (86) and complicate existing chronic diseases (87, 88). Poor nutrition can also impair the immune system and its defense against COVID-19 (89, 90). In fact, deficiencies in micronutrients such as vitamins $\mathrm{A}, \mathrm{C}, \mathrm{D}$, zinc, and iron have been associated with adverse clinical outcomes related to COVID-19 (91). Nutrition, including adequate protein intake and vitamin $\mathrm{D}$, is particularly important for low-income older adults during lockdowns and self-isolation to maintain muscle strength and balance (92) and prevent sarcopenia (93-95).

Low-income older adults are at an increased risk of sleep problems $(96,97)$. The pandemic situation has worsened older adults' sleep quality (42) and increased cases of insomnia (43). Older people with poor sleep quality also report greater levels of loneliness $(42,98)$, which have been linked to cardiovascular disease (99), dementia risk (100), poorer self-rated health (101), limited mobility (102), and premature death (47). General delays in seeking or obtaining medical care during the pandemic, including the cancellation of medical appointments for chronic disease care, may have also contributed to chronic disease complications and poor physical health of low-income older adults $(43,103,104)$.

\section{POSITIVE CONSEQUENCES OF THE COVID-19 PANDEMIC FOR LOW-INCOME OLDER ADULTS}

While the negative consequences of the pandemic far outweigh the benefits, some positive repercussions can be noted, especially for low-income older adults. A study by Whitehead and Torossian described the joys experienced by low-income older adults during the pandemic, which included interactions with family/friends, digital communication, hobbies/entertainment, and pets (105). For low-income older adults living with a partner or confined with family members in multigenerational households, for example, the pandemic may have provided the opportunity to create stronger and more meaningful connections with one another $(106,107)$. Low-income older adults with access to technology may have gained more confidence using technology and online platforms that helped them maintain their social interactions and engage in hobbies, such as reading and listening to music (52).

It is also possible that the chronic stress experienced by lowincome older adults throughout their lives may have helped them be more resilient during the pandemic, able to positively reframe the situation, and cope with these unusually stressful times (108111). Some may have also turned to religion and spirituality as resources to manage their emotional and economic stress and find purpose and meaning during the pandemic (112).

\section{INDIVIDUAL-LEVEL RECOMMENDATIONS FOR HEALTHY LIVING WITH NO OR LOW FINANCIAL COMMITMENT}

In Table 1, we summarize practical recommendations for healthful lifestyles among low-income older adults during the COVID-19 pandemic. Many of these recommendations may be universal for older adults and individuals of all ages and may also apply outside of pandemic situations. However, they are particularly pertinent during the pandemic because they are feasible for individuals with limited resources. While these recommendations arose from the experience of the COVID-19 pandemic, they may apply more broadly during times when physical distancing is required or recommended for older adults, such as during annual flu seasons.

\section{RECOMMENDATIONS FOR GOVERNMENTS, COMMUNITIES, AND ORGANIZATIONS}

Governments, communities, and organizations can play important roles to improve healthy living among low-income older adults during the COVID-19 pandemic. Governments can implement policies that encourage healthy behaviors among low-income older adults (119). They can also prioritize and invest financial resources in populations (e.g., low-income older adults) or specific areas of deprivation (e.g., mental and physical health, internet access) (120). Established community networks, such as those from age-friendly communities $(121,122)$, can be leveraged to encourage organizations to work together across organizational and sector boundaries to meet the urgent needs of its low-income older adult populations. For example, the City of Lethbridge, Canada was recognized for this type of work where more than 50 organizations collaborated across sectors to fight food insecurity of low-income older adults during the pandemic (123). Government policies and investments can ultimately lead to greater funding for organizations so they 
TABLE 1 | Practical recommendations for low-income older adults.

\begin{tabular}{|c|c|}
\hline Topic & Strategies \\
\hline Sleep (113) & $\begin{array}{l}\text { - Aim for 7-9 hours of sleep every night. } \\
\text { - Establish a sleep schedule. It is important to maintain a consistent time for going to bed and waking up every day. This means avoiding napping } \\
\text { in the late afternoon or evening before bedtime. Maintaining a sleep schedule will help the body establish a rhythm to help older adults fall } \\
\text { asleep easier and remain asleep longer. } \\
\text { - Establish a bedtime routine. Take time to decompress and relax before bed to increase your ability to fall asleep quickly. Reading a book or } \\
\text { listening to music are great pre-bed routines. Avoid using technology (e.g., watching TV, using your smart phone or tablet) in bed to reduce } \\
\text { over-stimulation. Additionally, avoid consuming large meals and/or caffeinated or alcoholic beverages in the hours before sleep as not to } \\
\text { disrupt sleep quality and duration. } \\
\text { - Create a conducive sleeping environment. Avoid unnecessary lighting and maintain a comfortable temperature that is neither too hot nor too } \\
\text { cold. Minimize the exposure to sources of noise when possible. If sounds from traffic, housemates, or neighbors are unavoidable, consider } \\
\text { earplugs or sources of white noise. }\end{array}$ \\
\hline $\begin{array}{l}\text { Physical activity } \\
(114-116)\end{array}$ & $\begin{array}{l}\text { - Break sedentary behavior every } 20-30 \text { minutes by walking or standing for } 2-5 \text { minutes. } \\
\text { - Engage in 150-300 minutes a week of moderate-intensity physical activity. This can be done } 10 \text { minutes at a time, if needed, and can be as } \\
\text { easy as taking a walk outside. Start slowly and build up your exercise time as you become more active. Also, consider stretching your muscles } \\
\text { when they are warm. } \\
\text { - Maintain your strength. Use your muscles as much as you can to avoid deconditioning that can increase your risk of falls. Strength training } \\
\text { can be as simple as doing a few repetitions of bicep curls and overhead presses with soup cans or heavy water bottles. Moving is key so use } \\
\text { the equipment that you have available at home. Avoid sitting down for long periods of time. } \\
\text { - Practice keeping your balance. Balance and strength are important to prevent falls and fall-related injuries. You can train your balance by } \\
\text { standing on one foot and then the other, or getting up from a chair without the support of your hands or arms. Go at your own pace and } \\
\text { stay safe. }\end{array}$ \\
\hline Nutrition (117) & $\begin{array}{l}\text { - Stay hydrated. Make sure you drink plenty of water throughout the day. } \\
\text { - Eat foods rich in nutrients. This includes foods like fruits and vegetables, whole grains, eggs, lean meats, fish, beans, and nuts. Maintain a high } \\
\text { level of energy throughout the day by eating a few healthy snacks. Maintaining consistent eating times can be helpful for weight management. } \\
\text { - Avoid foods filled with sugar, salt or saturated fat. Foods like chips, pastries, candy, ice cream, and soda contribute little nutritional value to } \\
\text { your diet. } \\
\text { - When possible, share meals with others. If you live with others, avoid dining alone. Invite others to eat with you or prepare a meal for the } \\
\text { household so you can eat while enjoying each other's company. Avoid eating in front of a screen as much as possible so that you can take } \\
\text { the time to enjoy the food you are eating. }\end{array}$ \\
\hline Stress (118) & $\begin{array}{l}\text { - Take care of yourself. Take some time during the day to take deep breaths. Slowly breathe in through the nose, focus on your breath as you } \\
\text { let the air fill your belly, and then slowly exhale through your nose or mouth. Repeat a few times until you feel more calm or relaxed. } \\
\text { - Make time to unwind at the end of every day. Engage in an activity that you enjoy such as reading a book, doing a puzzle, playing cards, } \\
\text { calling your family or friends, or speaking with your neighbors while maintaining physical distancing. } \\
\text { - Avoid consuming too much alcohol, tobacco, and other substances. These substances can aggravate symptoms of stress as well as } \\
\text { increase the risk of developing substance use disorders. }\end{array}$ \\
\hline
\end{tabular}

can increase their availability, accessibility, and affordability of programs and services, including providing mental healthcare and well-being resources for low-income older adults (124).

\section{DISCUSSION}

In this perspective, we described the physical and mental health challenges associated with lifestyle disruptions caused by the COVID-19 pandemic. Individual-level recommendations for sleep, physical activity, nutrition, and stress provide a helpful framework for achieving healthy habits in spite of our changing society; however, meeting these guidelines may be especially challenging for older adults who are economically disadvantaged, those with limited family or social networks, and/or those experiencing physical, cognitive, or sensory impairments. These older adult subpopulations are not typically the focal group for health recommendations, despite being at higher risk for poorer health status based on financial barriers for healthy living. This may make meeting guidelines and adhering to recommendations impossible based on their available resources and economic position. Additional efforts and research are needed to refine and tailor guidelines for older adults in "pandemic living situations" to ensure their ability to be universally adopted, regardless of income and resources. As one example, while older adults may be eligible for and receive home-delivered meals, they may not have much control over the foods they receive from these programs. However, older adults may still be able to implement some of the healthy eating tips such as consistent meal times, eating with others, and not eating in front of a screen. As another example, given the need to remain physically distant from others to avoid the virus, the nation has turned to virtual and telephone solutions to engage older adults with community, social, and healthcare services. While these forms of "distanced connectivity" (2) may have value for older adults, the digital divide prevents many low-income older adults from accessing and benefiting from such services. Many lower-income and rural areas do not have high-speed broadband, and low-income older adults may not have access to 
computers, smartphones, or tablets regardless of internet access. As such, governments, communities, and organizations have important roles to support and promote healthy living among low-income older adults during the COVID-19 pandemic. As the world undergoes unprecedented changes, and disparities and inequities widen in terms of resource availability, it is increasingly critical to provide realistic health recommendations to lowincome older adults to which they can reasonably adhere. As a society, we must implement system-level efforts to better support this population and complement their individual-level efforts for change.

\section{REFERENCES}

1. Centers for Disease Control and Prevention. COVID-19 Guidance for Older Adults. (2020). Available online at: https://www.cdc.gov/aging/covid19guidance.html (accessed December 1, 2020).

2. Smith ML, Steinman LE, Casey EA. Combatting social isolation among older adults in a time of physical distancing: The COVID-19 social connectivity paradox. Front Public Health. (2020) 8:403. doi: 10.3389/fpubh.2020.00403

3. Krendl AC, Perry BL. The impact of sheltering in place during the COVID19 pandemic on older adults' social and mental well-Being. J Gerontol Series B. (2021) 76:e53-8. doi: 10.1093/geronb/gbaa110

4. Visser M, Schaap LA, Wijnhoven HAH. Self-reported impact of the COVID-19 pandemic on nutrition and physical activity behaviour in dutch older adults living independently. Nutrients. (2020) 12:3708. doi: 10.3390/nu12123708

5. Grossman ES, Hoffman YSG, Palgi Y, Shrira A. COVID-19 related loneliness and sleep problems in older adults: Worries and resilience as potential moderators. Personal Individ Differ. (2021) 168:110371. doi: 10.1016/j.paid.2020.110371

6. Satre DD, Hirschtritt ME, Silverberg MJ, Sterling SA. Addressing problems with alcohol and other substances among older adults during the COVID-19 pandemic. Ame J Geriatric Psychiatry. (2020) 28:7803. doi: 10.1016/j.jagp.2020.04.012

7. Son JS, Nimrod G, West ST, Janke MC, Liechty T, Naar JJ. Promoting older adults' physical activity and social well-being during COVID-19. Leisure Sci. 43:287-94. doi: 10.1080/01490400.2020.1774015

8. Mollalo A, Vahedi B, Rivera KM. GIS-based spatial modeling of COVID-19 incidence rate in the continental United States. Sci Total Environt. (2020) 728:138884. doi: 10.1016/j.scitotenv.2020.138884

9. Vahia IV, Blazer DG, Smith GS, Karp JF, Steffens DC, Forester, et al. COVID-19, mental health and aging: a need for new knowledge to bridge science and service. Am J Geriatr Psychiatry. (2020) 28:6957. doi: $10.1016 /$ j.jagp.2020.03.007

10. Hawkins RB, Charles EJ, Mehaffey JH. Socio-economic status and COVID-19-related cases and fatalities. Public Health. (2020) 189:12934. doi: 10.1016/j.puhe.2020.09.016

11. Wiemers EE, Abrahams S, AlFakhri M, Hotz VJ, Schoeni RF, Seltzer JA. Disparities in vulnerability to complications from COVID-19 arising from disparities in preexisting conditions in the United States. Res Soc Stratif Mobil. (2020) 69. doi: 10.1016/j.rssm.2020.100553

12. McMaughan DJ, Oloruntoba O, Smith ML. Socioeconomic status and access to healthcare: interrelated drivers for healthy aging. Front Public Health. (2020) 8:231. doi: 10.3389/fpubh.2020.0 0231

13. Grant MJ, Booth A. A typology of reviews: an analysis of 14 review types and associated methodologies: A typology of reviews, Health Inform Libraries J. (2009) 26:91-108. doi: 10.1111/j.1471-1842.2009.00848.x

14. Congressional Research Service. Potential Impacts of the COVID-19 Pandemic on the Income Security of Older Americans. (2020). Available online at: https://fas.org/sgp/crs/misc/R46617.pdf (accessed December 15, 2020).

15. Social Security. Old-Age, Survivors, and Disability Insurance. Annual Statistical Supplement. (2019). Available online at: https://www.ssa.gov/

\section{DATA AVAILABILITY STATEMENT}

The original contributions presented in the study are included in the article/supplementary material, further inquiries can be directed to the corresponding author/s.

\section{AUTHOR CONTRIBUTIONS}

All authors significantly contributed to the planning, drafting, and review of this manuscript.

policy/docs/statcomps/supplement/2019/5a.html (accessed February 23, 2021).

16. Wapner J. Covid-19: medical expenses leave many Americans deep in debt. BMJ. (2020) 2020:m3097. doi: 10.1136/bmj.m3097

17. Fehr R, Cox C, Pollitz K, Cubanski J, Rudowitz R. Five Things to Know about the Cost of COVID-19 Testing and Treatment. (2020). Available online at: https://www.kff.org/coronavirus-covid-19/issue-brief/five-thingsto-know-about-the-cost-of-covid-19-testing-and-treatment/ (accessed December 15, 2020).

18. Li Y, Mutchler JE. Older adults and the economic impact of the COVID-19 pandemic. I Aging Soc Policy. (2020) 32:47787. doi: $10.1080 / 08959420.2020 .1773191$

19. Powell T, Bellin E, Ehrlich AR. Older adults and Covid-19: the most vulnerable, the hardest hit. Hastings Center Rep. (2020) 50:613. doi: $10.1002 /$ hast.1136

20. Gaffney AW, Hawks L, Bor DH, Woolhandler S, Himmelstein DU, McCormick D. 18.2 million individuals at increased risk of severe COVID19 illness are un- or underinsured. J Gen Intern Med. (2020) 35:24879. doi: $10.1007 /$ s11606-020-05899-8

21. Abedi V, Olulana O, Avula V, Chaudhary D, Khan A, Shahjouei S, et al. Racial, economic, and health inequality and COVID-19 infection in the United States. J Racial and Ethnic Health Disparities. (2020) 8:73242. doi: 10.1007/s40615-020-00833-4

22. Snowden LR, Graaf G. COVID-19, social determinants past, present, and future, and African Americans' health. J Racial and Ethnic Health Disparities. (2020) 8:12-20. doi: 10.1007/s40615-020-00923-3

23. Yancy CW. COVID-19 and African Americans. JAMA. (2020) 323:1891. doi: 10.1001/jama.2020.6548

24. Garcia MA, Homan PA, García C, Brown TH. The color of COVID19: structural racism and the disproportionate impact of the pandemic on older black and latinx adults. J Gerontol: Series B. (2020) 2020:gbaa114. doi: 10.1093/geronb/gbaa114

25. Clark E, Fredricks K, Woc-Colburn L, Bottazzi ME, Weatherhead J. Disproportionate impact of the COVID-19 pandemic on immigrant communities in the United States. PLoS Negl Trop Dis. (2020) 14:e0008484. doi: 10.1371/journal.pntd. 0008484

26. Ray R. Why are Blacks Dying at Higher Rates From COVID-19? (2020). Available online at: https://www.brookings.edu/blog/fixgov/2020/04/09/ why-are-blacks-dying-at-higher-rates-from-covid-19/ (accessed December $15,2020)$.

27. Wolfson JA, Leung CW. Food insecurity and COVID-19: disparities in early effects for US adults. Nutrients. (2020) 12:1648. doi: 10.3390/nu12061648

28. Ziliak JP, Gundersen C. The State of Senior Hunger in American 2018: An Annual Report. Feeding America. (2020) Available online at: https://www. feedingamerica.org/sites/default/files/2020-05/2020-The\%20State\%20of \%20Senior\%20Hunger\%20in\%202018.pdf (accessed December 15, 2020).

29. Niles MT, Bertmann F, Belarmino EH, Wentworth T, Biehl E, Neff RA. The Early Food Insecurity Impacts of COVID-19. Nutrition. (2020) 12:2096. doi: 10.1101/2020.05.09.20096412

30. Mazzella R. How Covid-19 Is Impacting Food Insecurity for Older Adults. (2020). Available online at: https://www.forbes.com/sites/nextavenue/2020/ 
05/31/how-covid-19-is-impacting-food-insecurity-for-older-adults/?sh= 4a737094539c (accessed December 15, 2020).

31. Iob E, Frank P, Steptoe A, Fancourt D. Levels of severity of depressive symptoms among at-risk groups in the UK during the COVID-19 pandemic. JAMA Netw Open. (2020) 3:e2026064. doi: 10.1001/jamanetworkopen.2020.26064

32. Jaspal R, Breakwell GM. Socio-economic inequalities in social network, loneliness and mental health during the COVID-19 pandemic. Int J Soc Psychiatry. (2020) 2020:002076402097669. doi: 10.1177/0020764020976694

33. Brooks SK, Webster RK, Smith LE, Woodland L, Wessely S, Greenberg N, et al. The psychological impact of quarantine and how to reduce it: rapid review of the evidence. Lancet. (2020) 395:912-20. doi: 10.1016/S0140-6736(20)30460-8

34. Kontoangelos K, Economou M, Papageorgiou C. Mental health effects of COVID-19 pandemia: a review of clinical and psychological traits. Psychiatry Investig. (2020) 17:491-505. doi: 10.30773/pi.2020.0161

35. Bo H-X, Li W, Yang Y, Wang Y, Zhang Q, Cheung T, et al. Posttraumatic stress symptoms and attitude toward crisis mental health services among clinically stable patients with COVID-19 in China. Psychol Med. (2020) 51:1052-3. doi: 10.1017/S0033291720000999

36. Gyasi RM. Fighting COVID-19: fear and internal conflict among older adults in ghana. J Gerontol Soc Work. (2020) 63:688-90. doi: 10.1080/01634372.2020.1766630

37. D'cruz M, Banerjee D. An invisible human rights crisis': The marginalization of older adults during the COVID-19 pandemic - An advocacy review. Psychiatry Res. (2020) 292:113369. doi: 10.1016/j.psychres.2020.113369

38. Lee S. COVID-19 amplifiers on health inequity among the older populations. Front Public Health. (2021) 8:609695. doi: 10.3389/fpubh.2020.609695

39. Seifert A. The digital exclusion of older adults during the COVID-19 pandemic. J Gerontol Soc Work. (2020) 63:6746. doi: 10.1080/01634372.2020.1764687

40. Saltzman LY, Hansel TC, Bordnick PS. Loneliness, isolation, and social support factors in post-COVID-19 mental health. Psychol Trauma. (2020) 12:S55-7. doi: $10.1037 /$ tra0000703

41. Adhanom Ghebreyesus T. Addressing mental health needs: an integral part of COVID-19 response. World Psychiatry. (2020) 19:129-30. doi: 10.1002/wps.20768

42. Groarke JM, Berry E, Graham-Wisener L, McKenna-Plumley PE, McGlinchey E, Armour C. Loneliness in the UK during the COVID-19 pandemic: Cross-sectional results from the COVID-19 Psychological Wellbeing Study. PLOS ONE. (2020) 15:e0239698. doi: 10.1371/journal.pone.0239698

43. Wong SYS, Zhang D, Sit RWS, Yip BHK, Chung RY, Wong CKM, et al. Impact of COVID-19 on loneliness, mental health, and health service utilisation: a prospective cohort study of older adults with multimorbidity in primary care. Br J Gen Pract. (2020) 70:e817-24. doi: 10.3399/bjgp20X713021

44. van Tilburg TG, Steinmetz S, Stolte E, van der Roest H, de Vries DH. Loneliness and mental health during the COVID-19 pandemic: a study among dutch older adults. J Gerontol Series B. (2020) 2020:gbaa111. doi: 10.1093/geronb/gbaa111

45. Wu B. Social isolation and loneliness among older adults in the context of COVID-19: a global challenge. Glob Health Res Policy. (2020) 5:27. doi: 10.1186/s41256-020-00154-3

46. Jeste DV, Lee EE, Cacioppo S. Battling the modern behavioral epidemic of loneliness: suggestions for research and interventions. JAMA Psychiatry. (2020) 77:553. doi: 10.1001/jamapsychiatry.2020.0027

47. Committee on the Health and Medical Dimensions of Social Isolation and Loneliness in Older Adults, Board on Health Sciences Policy, Board on Behavioral, Cognitive, and Sensory Sciences, Health and Medicine Division, Division of Behavioral and Social Sciences and Education, National Academies of Sciences, Engineering, and Medicine. Social Isolation and Loneliness in Older Adults: Opportunities for the Health Care System. National Academies Press (2020). doi: 10.17226/25663

48. Health Resources \& Services Administration. The "Loneliness Epidemic". (2019). Available online at: https://www.hrsa.gov/enews/past-issues/2019/ january-17/loneliness-epidemic (accessed January 5, 2021).

49. Choi NG, DiNitto DM. The digital divide among low-income homebound older adults: internet use patterns, ehealth literacy, and attitudes toward computer/internet use. J Med Internet Res. (2013) 15:e93. doi: 10.2196/jmir.2645

50. Fraser S, Lagacé M, Bongué B, Ndeye N, Guyot J, Bechard L, et al. Ageism and COVID-19: what does our society's response say about us? Age Ageing. (2020) 2020:afaa097. doi: 10.1093/ageing/afaa097

51. Monahan C, Macdonald J, Lytle A, Apriceno M, Levy SR. COVID-19 and ageism: how positive and negative responses impact older adults and society. Am Psychol. (2020) 75:887-96. doi: 10.1037/amp0000699

52. Morrow-Howell N, Galucia N, Swinford E. Recovering from the COVID19 pandemic: a focus on older adults. J Aging Soc Policy. (2020) 32:52635. doi: 10.1080/08959420.2020.1759758

53. Levy BR, Slade MD, Kunkel SR, Kasl SV. Longevity increased by positive self-perceptions of aging. J Personal Soc Psychol. (2002) 83:26170. doi: 10.1037/0022-3514.83.2.261

54. Pollard MS, Tucker JS, Green HD. Changes in adult alcohol use and consequences during the COVID-19 pandemic in the US. JAMA Netw Open. (2020) 3:e2022942. doi: 10.1001/jamanetworkopen.2020.22942

55. Courtet P, Olié E, Debien C, Vaiva G. Keep socially (but not physically) connected and carry on: preventing suicide in the age of COVID-19. J Clin Psychiatry. (2020) 81:13370. doi: 10.4088/JCP.20com13370

56. Harris EC, Barraclough B. Suicide as an outcome for mental disorders: A meta-analysis. Br J Psychiatry. (1997) 170:205-28. doi: 10.1192/bjp.170.3.205

57. El Ibrahimi S, Xiao Y, Bergeron CD, Beckford N, Virgen E, Smith ML. Suicide distribution and trends among older adult males in the United States, 1999-2018. Am J Prevent Med. (2021) 60:80211. doi: 10.1016/j.amepre.2020.12.021

58. Moreno C, Wykes T, Galderisi S, Nordentoft M, Crossley N, Jones $\mathrm{N}$, et al. How mental health care should change as a consequence of the COVID-19 pandemic. Lancet Psychiatry. (2020) 7:813-24. doi: 10.1016/S2215-0366(20)30307-2

59. Pelicioni PHS, Lord SR. COVID-19 will severely impact older people's lives, and in many more ways than you think! Brazil J Phys Therapy. (2020) 24:293-4. doi: 10.1016/j.bjpt.2020.04.005

60. Castañeda-Babarro A, Arbillaga-Etxarri A, Gutiérrez-Santamaria B, Coca A. Impact of COVID-19 confinement on the time and intensity of physical activity in the Spanish Population. Int J Environ Res Public Health. (2020) 18:369. doi: 10.21203/rs.3.rs-26074/v1

61. Goethals L, Barth N, Guyot J, Hupin D, Celarier T, Bongue B. Impact of home quarantine on physical activity among older adults living at home during the COVID-19 pandemic: qualitative interview study. JMIR Aging. (2020) 3:e19007. doi: 10.2196/19007

62. Suzuki Y, Maeda N, Hirado D, Shirakawa T, Urabe Y. Physical activity changes and its risk factors among community-dwelling japanese older adults during the COVID-19 epidemic: associations with subjective well-being and health-related quality of life. IJERPH. (2020) 17:6591. doi: 10.3390/ijerph17186591

63. Cunningham C, O' Sullivan R. Why physical activity matters for older adults in a time of pandemic. Eur Rev Aging Phys Act. (2020) 17:16. doi: 10.1186/s11556-020-00249-3

64. Constandt B, Thibaut E, De Bosscher V, Scheerder J, Ricour M, Willem A. Exercising in times of lockdown: an analysis of the impact of COVID-19 on levels and patterns of exercise among adults in Belgium. IJERPH. (2020) 17:4144. doi: 10.3390/ijerph17114144

65. Browne RAV, Macêdo GAD, Cabral LLP, Oliveira GTA, Vivas A, Fontes EB, et al. Initial impact of the COVID-19 pandemic on physical activity and sedentary behavior in hypertensive older adults: An accelerometer-based analysis. Experi Gerontol. (2020) 142:111121. doi: 10.1016/j.exger.2020.111121

66. da Silva JM, Verlengia R, de Oliveira JJ, Ribeiro AGSV, Barbosa CGR, Stotzer US, et al. Associations between sociodemographic factors and physical activity and sedentary behaviors in adults with chronic diseases during COVID-19 pandemic. Sports Med Health Sci. (2020) 2:216-20. doi: 10.1016/j.smhs.2020.1 1.002

67. Meyer J, Herring M, McDowell C, Lansing J, Brower C, Schuch F, et al. Joint prevalence of physical activity and sitting time during COVID-19 among US adults in April 2020. Prevent Med Rep. (2020) 20:101256. doi: 10.1016/j.pmedr.2020.101256 
68. Bowden Davies KA, Pickles S, Sprung VS, Alam U, Moore DR, Tahrani AA, et al. Reduced physical activity in young and older adults: metabolic and musculoskeletal implications. Therap Adv Endocrinol. (2019) 10:204201881988882. doi: 10.1177/2042018819888824

69. Roschel H, Artioli GG, Gualano B. Risk of increased physical inactivity during COVID-19 outbreak in older people: a call for actions. J Am Geriatr Soc. (2020) 68:1126-8. doi: 10.1111/jgs.16550

70. Reidy PT, McKenzie AI, Mahmassani Z, Morrow VR, Yonemura NM, Hopkins PN, et al. Skeletal muscle ceramides and relationship with insulin sensitivity after 2 weeks of simulated sedentary behaviour and recovery in healthy older adults: Inactivity, insulin resistance and ceramide in ageing. $J$ Physiol. (2018) 596:5217-36. doi: 10.1113/JP276798

71. Vitman Schorr A, Yehuda I, Tamir S. Loneliness, malnutrition and change in subjective age among older adults during COVID-19 pandemic. IJERPH. (2020) 18:106. doi: 10.3390/ijerph18010106

72. Said CM, Batchelor F, Duque G. Physical activity and exercise for older people during and after the coronavirus disease 2019. Pandemic: a path to recovery. J Am Med Direct Assoc. (2020) 21:977-9. doi: 10.1016/j.jamda.2020.06.001

73. Bergeron CD, Cohen SA, Smith ML. Mobility and falls among older adults in the United States. In: Jurkowski ET, Guest MA, editors. Social Determinants of Healthy Aging: A Public Health Perspective. Washington, DC: APHA Press.

74. Marçal IR, Fernandes B, Viana AA, Ciolac EG. The urgent need for recommending physical activity for the management of diabetes during and beyond COVID-19 outbreak. Front Endocrinol. (2020) 11:584642. doi: 10.3389/fendo.2020.584642

75. Damiot A, Pinto AJ, Turner JE, Gualano B. Immunological implications of physical inactivity among older adults during the COVID-19 pandemic. Gerontology. (2020) 66:431-8. doi: 10.1159/000509216

76. Hamilton MT, Hamilton DG, Zderic TW. Sedentary Behavior as a Mediator of Type 2 Diabetes. In: Goedecke JH, Ojuka EO, editors. Medicine Sport Science. S. KARGER AG (Basel). (2014).

77. Breen L, Stokes KA, Churchward-Venne TA, Moore DR, Baker SK, Smith $\mathrm{K}$, et al. Two weeks of reduced activity decreases leg lean mass and induces "anabolic resistance" of myofibrillar protein synthesis in healthy elderly. $J$ Clin Endocrinol Metabol. (2013) 98:2604-12. doi: 10.1210/jc.2013-1502

78. Booth FW, Roberts CK, Laye MJ. Lack of exercise is a major cause of chronic diseases. In: Terjung R, editor. Comprehensive Physiology. Hoboken, NJ: John Wiley \& Sons, Inc. (2012). doi: 10.1002/cphy.c110025

79. Anderson E, Durstine JL. Physical activity, exercise, and chronic diseases: A brief review. Sports Med Health Sci. (2019) 1:3-10. doi: 10.1016/j.smhs.2019.08.006

80. Ströhle A. Physical activity, exercise, depression and anxiety disorders. $J$ Neural Transm. (2009) 116:777-84. doi: 10.1007/s00702-008-0092-x

81. Steptoe A, Zaninotto P. Lower socioeconomic status and the acceleration of aging: An outcome-wide analysis. Proc Natl Acad Sci USA. (2020) 117:149117. doi: $10.1073 /$ pnas. 1915741117

82. Minkler M, Fuller-Thomson E, Guralnik JM. Gradient of disability across the socioeconomic spectrum in the United States. $N$ Engl J Med. (2006) 355:695-703. doi: 10.1056/NEJMsa04 4316

83. Callow DD, Arnold-Nedimala NA, Jordan LS, Pena GS, Won J, Woodard $\mathrm{JL}$, et al. The mental health benefits of physical activity in older adults survive the COVID-19 pandemic. Am J Geriatr Psychiatry. (2020) 28:104657. doi: 10.1016/j.jagp.2020.06.024

84. Smith ML, Bergeron CD, Lachenmayr S, Eagle LA, Simon JR. A brief intervention for malnutrition among older adults: stepping up your nutrition. IJERPH. (2020) 17:3590. doi: 10.3390/ijerph17103590

85. Mangels AR. Malnutrition in older adults. AJN. (2018) 118:3441. doi: 10.1097/01.NAJ.0000530915.26091.be

86. Butler MJ, Barrientos RM. The impact of nutrition on COVID-19 susceptibility and long-term consequences. Brain Behav Immunity. (2020) 87:53-4. doi: 10.1016/j.bbi.2020.04.040

87. Ojo O. Nutrition and chronic conditions. Nutrients. (2019) 11:459. doi: 10.3390/nu11020459

88. Cano N, Melchior J-C. Malnutrition in chronic diseases. Rev Prat. (2003) 53:268-73.
89. Jaggers GK, Watkins BA, Rodriguez RL. COVID-19: repositioning nutrition research for the next pandemic. Nutrition Research. (2020) 81:16. doi: 10.1016/j.nutres.2020.07.005

90. Radwan E, Radwan A, Radwan W. Challenges facing older adults during the COVID-19 outbreak. Eur J Env Publi. (2020) 5:em0059. doi: 10.29333/ejeph/8457

91. Akhtar S, Das JK, Ismail T, Wahid M, Saeed W, Bhutta ZA. Nutritional perspectives for the prevention and mitigation of COVID-19. Nutr Rev. (2020) 2020:nuaa063. doi: 10.1093/nutrit/nuaa063

92. Naseeb MA, Volpe SL. Protein and exercise in the prevention of sarcopenia and aging. Nutr Res. (2017) 40:1-20. doi: 10.1016/j.nutres.2017.01.001

93. Sieber CC. Malnutrition and sarcopenia. Aging Clin Exp Res. (2019) 31:7938. doi: 10.1007/s40520-019-01170-1

94. Beaudart C, Sanchez-Rodriguez D, Locquet M, Reginster J-Y, Lengelé L, Bruyère $O$. Malnutrition as a strong predictor of the onset of sarcopenia. Nutrients. (2019) 11:2883. doi: 10.3390/nu11122883

95. Remelli F, Vitali A, Zurlo A, Volpato S. Vitamin D Deficiency and Sarcopenia in Older Persons. Nutrients. (2019) 11:2861. doi: 10.3390/nu11122861

96. Chen J-H. Experience of poverty and problem sleep in later life. Res Aging. (2019) 41:697-722. doi: 10.1177/0164027519834861

97. Wu W, Wang W, Dong Z, Xie Y, Gu Y, Zhang Y, et al. Sleep quality and its associated factors among low-income adults in a rural area of China: a population-based study. IJERPH. (2018) 15:2055. doi: 10.3390/ijerph15092055

98. Losada-Baltar A, Jiménez-Gonzalo L, Gallego-Alberto L, Pedroso-Chaparro M del S, Fernandes-Pires J, Márquez-González M. "We are staying at home." Association of Self-perceptions of Aging. J Gerontol Series B. (2020) 2020:gbaa048. doi: 10.1093/geronb/gbaa048

99. Valtorta NK, Kanaan M, Gilbody S, Ronzi S, Hanratty B. Loneliness and social isolation as risk factors for coronary heart disease and stroke: systematic review and meta-analysis of longitudinal observational studies. Heart. (2016) 102:1009-16. doi: 10.1136/heartjnl-2015-308790

100. Kuiper JS, Zuidersma M, Oude Voshaar RC, Zuidema SU, van den Heuvel ER, Stolk RP, et al. Social relationships and risk of dementia: A systematic review and meta-analysis of longitudinal cohort studies. Ageing Res Rev. (2015) 22:39-57. doi: 10.1016/j.arr.2015.04.006

101. Richard A, Rohrmann S, Vandeleur CL, Schmid M, Barth J, Eichholzer M. Loneliness is adversely associated with physical and mental health and lifestyle factors: Results from a Swiss national survey. PLOS ONE. (2017) 12:e0181442. doi: 10.1371/journal.pone.0181442

102. Perissinotto CM, Stijacic Cenzer I, Covinsky KE. Loneliness in older persons: a predictor of functional decline and death. Arch Intern Med. (2012) 172:1993. doi: 10.1001/archinternmed.2012.1993

103. Czeisler MÉ, Marynak K, Clarke KEN, Salah Z, Shakya I, Thierry JM, et al. Delay or avoidance of medical care because of COVID-19-related concerns - United States, June (2020). MMWR Morb Mortal Wkly Rep. (2020) 69:1250-7. doi: 10.15585/mmwr.mm6936a4

104. Oseran AS, Nash D, Kim C, Moisuk S, Lai P-Y, Pyhtila J, et al. Changes in hospital admissions for urgent conditions during COVID-19 pandemic. Am J Manag Care. (2020) 26:327-8. doi: 10.37765/ajmc.2020.43837

105. Whitehead BR, Torossian E. Older adults' experience of the COVID-19 pandemic: a mixed-methods analysis of stresses and joys. Gerontologist. (2021) 61:36-47. doi: 10.1093/geront/gnaa126

106. Organisation for Economic Cooperation and Development. COVID-19: Protecting People and Societies. (2020). Available online at: https://www. oecd.org/coronavirus/policy-responses/covid-19-protecting-people-andsocieties-e5c9de1a/ (accessed May 30, 2021).

107. Okabe-Miyamoto K, Folk D, Lyubomirsky S, Dunn EW. Changes in social connection during COVID-19 social distancing: It's not (household) size that matters, it's who you're with. PLoS ONE. (2021) 16:e0245009. doi: 10.1371/journal.pone.0245009

108. Vahia IV, Jeste DV, Reynolds CF. Older adults and the mental health effects of COVID-19. JAMA. (2020) 324:2253. doi: 10.1001/jama.2020.21753

109. Babulal GM, Torres VL, Acosta D, Agüero C, Aguilar-Navarro S, Amariglio $\mathrm{R}$, et al. The impact of COVID-19 on the well-being and cognition of older adults living in the United States and Latin America. EClinicalMedicine. (2021) 35:100848. doi: 10.1016/j.eclinm.2021.100848 
110. Laird KT, Krause B, Funes C, Lavretsky H. Psychobiological factors of resilience and depression in late life. Transl Psychiatry. (2019) 9:88. doi: 10.1038/s41398-019-0424-7

111. Smith ML, Bergeron CD, McCord CE, Hochhalter AK, Ory MG. Successful aging and resilience: applications for public health, health care, and policy. In: Resnick B, Gwyther LP, Roberto KA, editors. Resilience in Aging. Cham: Springer International Publishing (2018). doi: 10.1007/978-3-030-04 555-5_2

112. Hamilton JB, Best NC, Barney TA, Worthy VC, Phillips NR. Using spirituality to cope with COVID-19: the experiences of African American breast cancer survivors. J Canc Educ. (2021) 17:1-7. doi: 10.1007/s13187-021-01974-8

113. National Institute on Aging. AgePage: A Good Night's Sleep. (2018). Available online at: https://order.nia.nih.gov/sites/default/files/2018-05/a good_nights_sleep.pdf (accessed February 23, 2021).

114. National Institute on Aging. AgePage: Exercise and Physical Activity: Getting Fit for Life. (2019). Available online at: https://order.nia.nih.gov/sites/default/ files/2019-06/AgePage-exercise-physical-activity.pdf (accessed February 23, 2021).

115. U.S. Department of Health and Human Services. Physical Activity Guidelines for Americans, 2nd edition. (2018). Available online at: https://health.gov/ sites/default/files/2019-09/Physical_Activity_Guidelines_2nd_edition.pdf (accessed May 30, 2021).

116. Paterson C, Fryer S, Zieff G, Stone K, Credeur DP, Barone Gibbs B, et al. The effects of acute exposure to prolonged sitting, with and without interruption, on vascular function among adults: a meta-analysis. Sports Med. (2020) 50:1929-42. doi: 10.1007/s40279-020-01325-5

117. National Institute on Aging. Smart Food Choices for Healthy Aging. (2019). Available online at: https://www.nia.nih.gov/health/smart-food-choiceshealthy-aging (accessed March 1, 2021).

118. Centers for Disease Control and Prevention. Coping with Stress. (2021). Available online at: https://www.cdc.gov/coronavirus/2019-ncov/daily-lifecoping/managing-stress-anxiety.html (accessed February 23, 2021).
119. Zieff G, Bates LC, Kerr ZY, Moore JB, Hanson ED, Battaglini C, et al. Targeting sedentary behavior as a feasible health strategy during COVID-19. Translat Behav Meds. (2021) 11:826-31. doi: 10.1093/tbm/ibaa101

120. Buffel T, Doran P, Goff M, Lang L, Lewis C, Phillipson C, et al. Covid-19 and inequality: developing an age-friendly strategy for recovery in low income communities. QAOA. (2020) 21:271-9. doi: 10.1108/QAOA-09-2020-0044

121. Steels S. Key characteristics of age-friendly cities and communities: A review. Cities. (2015) 47:45-52. doi: 10.1016/j.cities.2015.02.004

122. Marston HR, Shore L, White PJ. How does a (Smart) Age-Friendly Ecosystem Look in a Post-Pandemic Society? IJERPH. (2020) 17:8276. doi: 10.3390/ijerph17218276

123. World Health Organization. Lethbridge Helping Organizations COVID-19 Response. (2020). Available online at: https://www.who.int/news-room/ feature-stories/detail/lethbridge-helping-organizations-covid-19-response (accessed May 31, 2021).

124. Bergeron CD, Smith ML. The impact of physical challenges on the mental health of the aging population. In: Maller KLD, editor. The Praeger Handbook of Mental Health and the Aging Community. Santa Barbara, CA: Praeger (2018).

Disclaimer: This work does not represent the views of the Government of Canada.

Conflict of Interest: The authors declare that the research was conducted in the absence of any commercial or financial relationships that could be construed as a potential conflict of interest.

Copyright (C) 2021 Bergeron, Boolani, Jansen and Smith. This is an open-access article distributed under the terms of the Creative Commons Attribution License (CC $B Y)$. The use, distribution or reproduction in other forums is permitted, provided the original author(s) and the copyright owner(s) are credited and that the original publication in this journal is cited, in accordance with accepted academic practice. No use, distribution or reproduction is permitted which does not comply with these terms. 